\title{
A KINESTHETIC MOTOR IMAGERY STUDY IN PATIENTS WITH WRITER'S CRAMP
}

\author{
Vitor Tumas ${ }^{7}$, Americo C. Sakamoto ${ }^{7}$
}

\begin{abstract}
The aim was to determine if patients with writer's cramp (WC) have abnormalities in kinesthetic motor imagery of hand movements. We timed the execution and simulation of a "finger tap task" and a "writing task" in 9 patients with simple WC and 9 matched healthy controls. In the "finger tap task, patients tended to be slower than controls to execute without vision $(p=0.190)$ and to simulate the movements $(p=0.094)$. In the "writing task", patients were slower than controls to execute writing with vision $(p=0.0001)$ and without vision of the movements $(p=0.0001)$ and to mentally simulate it $(p=0.04)$. Patients were slower to execute writing than to simulate it $(p=0.021)$ In general, there were not significant correlations between times of execution and simulation of both tasks. In conclusion, patients with WC seem to have slowing in the processes of mental simulation of hand movements that is not specific for writing.
\end{abstract}

KEY WORDS: writer's cramp, task-specific dystonia, motor imagery.

\section{Estudo da imagem motora cinestésica em pacientes com cãibra do escrivão}

Resumo - O objetivo do estudo foi determinar se pacientes com cãibra do escrivão (CE) teriam anormalidades na imagem motora de movimentos manuais. Foi cronometrado o tempo gasto para a execução e simulação de uma tarefa de "batida dos dedos" e outra de "escrita" em 9 pacientes com CE simples e 9 controles pareados. Na tarefa de "batida dos dedos" os pacientes apresentaram tendência a serem mais lentos que os controles para executá-la com visão dos movimentos $(p=0,190)$ e para simulá-la $(p=0,094)$. Na tarefa de "escrita", os pacientes foram mais lentos que os controles para executá-la com visão ( $p=0.0001)$ e sem visão dos movimentos $(p=0,0001)$ e também para simulá-la $(p=0,04)$. Os pacientes foram mais lentos para escrever que para simular a escrita $(p=0,021)$. Não encontramos correlação entre os tempos de execução e simulação das tarefas. Pacientes com CE apresentam alentecimento no processo de simulação mental de movimentos manuais.

PALAVRAS-CHAVE: cãibra do escrivão, distonia tarefa-específica, imagem motora.

Kinestethic motor imagery (KMI) is the process of mental simulation of voluntary movements. There are many experimental findings demonstrating that a motor image is endowed with almost the same properties as those of the corresponding motor execution'. For instance, the timing of mental simulation of movements is described as closely similar ${ }^{2,3}$ to the real movement times ${ }^{4}$. Moreover, $\mathrm{KMI}$ activates cerebral areas involved in the execution of movements and the basal ganglia are one of the main regions activated ${ }^{1,5}$. Dysfunctions of the basal ganglia due to neurological diseases like Parkinson's disease impair $\mathrm{KMI}^{2}$. It could be expected that other pathological processes affecting this system could also be associ- ated with abnormalities in KMI. Writer's cramp (WC) is a common focal task-specific dystonia with an incompletely understood pathophysiology, but undoubtley linked to dysfunctions of the basal ganglia system ${ }^{6}$. WC is characterized by involuntary muscular contractions of the upper limb when the patient writes, that result in abnormal posturing, pain and loss of control of the pen?

Although the main motor abnormalities are evident during the execution of hand movements, there are neurophysiological and neuroimaging studies indicating that patients with WC also have disturbances in motor planning processes ${ }^{8-11}$. In simple WC the motor abnormalities are present during writing, while the performance in oth-

'MD, PhD, Professor of the Department of Neurology, Psychiatry and Medical Psychology, Ribeirão Preto School of Medicine, University of São Paulo, Ribeirão Preto SP, Brazil.

Received 7 October 2008, received in final form 14 January 2009. Accepted 9 April 2009.

Dr. Vitor Tumas - Department of Neurology, Psychiatry and Medical Psychology / Ribeirão Preto School of Medicine - University of São Paulo - Campus Universitário Monte Alegre - 14049-900 Ribeirão Preto SP - Brasil.E-mail: tumasv@rnp.fmrp.usp.br 
er manual tasks seems to be spared. The task-specificity of the motor disturbance suggests that the abnormalities in motor control may be linked to disruption of a specific motor plan or of a specific linkage between the motor program and its effector ${ }^{6}$.

It was our aim to search for the presence of KMI abnormalities in paients with simple WC. We hypothesized that if there was a specific temporal slowing in the flow of motor subroutines during motor planning of writing, we should also expect a proportional time delay in the mental simulation of the hand movements.

\section{METHOD}

\section{Patients and control subject}

Consecutive patients with clinical diagnosis of simple WC with slight disability and legible handwriting that were able to perform the motor tasks carried out in our study were included. Dystonia was scored using the Burke-Fahn-Marsden dystonia rating scale ${ }^{12}$. For comparison, we evaluated healthy control subjects matched for age, sex and educational level that were tested under the same experimental conditions than the patients. All subjects gave written informed consent to participate in this study that was previously approved by the Local Ethics Committee.

\section{The motor task}

In a single experimental session subjects were requested to execute and simulate with the dominant hand two distinct manual motor tasks: the "finger tap task" and the "writing task". At the beginning of the session all subjects were briefly instructed and trained to execute both tasks until they could neatly execute them. Next, the subjects were trained for imagery of the manual tasks avoiding the execution of the movements. They were instructed to simulate the movements exactly as they had executed them. The training time was extended until subjects rated their movement imagination vividly with a score of at least 7 on a 0 to 10 visual analogue scale.

The performance of each subject was measured by the time spent to execute or mentally simulate the tasks (performance time - PT). During the experimental session, one of the authors (VT) ordered the subject to begin his performance at the same time as he activated a hand-held digital chronograph. When the performance was completed by the subject under assessment, he should say: "end", which was the signal for the examiner to stop the timing. The subjects were continuously monitored during their performances. During the execution of the tasks the examiner could reject the performance if he detected faulty execution of the task or if the subject took delayed to give the stop order to the examiner.

Each motor task was performed under three distinct conditions: (1) motor execution of the task under visual control of the movements (execution with vision); (2) motor execution of the task with eyes closed (execution without vision); (3) mental simulation of the task with eyes closed (simulation). Each subject performed the task 5 times in each condition. The simulation of the tasks was performed with the subject keeping the same posture as used for motor execution.

At the beginning of the experimental session each subject was randomly assigned to first perform the "finger tap task" or the "writing task". Then, the subject was supposed to complete the 5 performances for each of the 3 conditions (execution with vision, execution without vision or simulation), randomly concluding a total of 15 trials for each task. After that, he repeated the same procedure for the second task.

\section{The "finger tap task"}

Subjects were comfortably seated with the right elbow supported on a table, and they were instructed to touch the pad of the thumb with the pad of the second to the fifth fingers successively and repetitively for five times. The subject was instructed to open his fingers wide before each closure and to perform the closures accurately but as quickly as possible.

\section{The "writing task"}

Subjects were comfortably seated with the right forearm supported on a table and holding a standardized pen in their habitual writing position. A blank sheet of paper (letter size) was fixed to the table with scotch tape and positioned according to each subject's choice. They were instructed to write using cursive style a standardized sentence: "Ribeirão Preto, 1 de janeiro de 2007", as quickly but as legibly and neatly as possible.

During the execution of the motor tasks the non-dominant hand was allowed to rest in the most confortable position for the subject but without touching any upper body part.

\section{Statistical analysis}

The PT were calculated as the mean of the set of 5 measures of performance in each condition. We used the non-parametric Friedman test and the Wilcoxon Signed Rank Tests for comparisons of PT within groups, and the Mann-Whitney test for comparisons between groups. We also calculated the correlations between the PTs in each group using the Spearman's correlation coefficient. Statistical level of significance was set at $\mathrm{p}<0.05$.

\section{RESULTS}

We included 9 right-handed WC patients, 5 males and 4 females aged 23 to 56 years (mean: 34.3 years) with total dystonia score ranging from 1 to 2 . They were not taking any symptomatic medication for dystonia nor had they been previously injected with botulinum toxin. All had a high educational level and presented abnormal posturing only during writing, without functional problems with other manual tasks. Their neurological examination was otherwise normal, except for the task-specific dystonia. For comparison we evaluated 9 right-handed healthy subjects, 5 males and 4 females, ranging in age from 24 to 


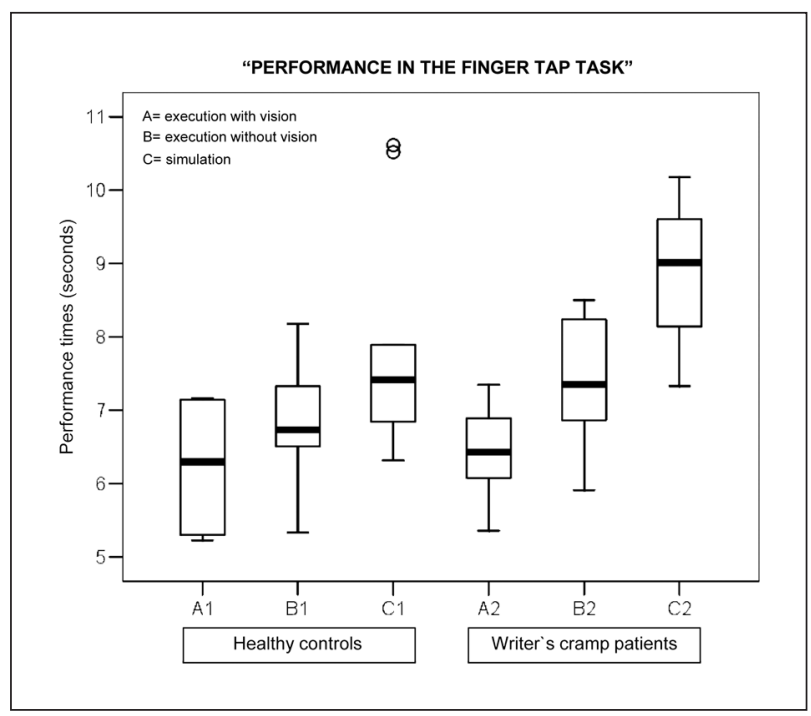

Fig 1. Box plot showing the performances of WC patients and healthy controls in the "finger tap task". The performances of patients and controls did not differed significantly but patients with WC had a tendency to be slower than controls for the motor execution without vision $(p=0.190)$ and specialy for the mental simulation of the movements $(p=0.094)$. Patients and controls were significantly slower to mentally simulate and to execute the task without visual control of the movements than to execute the task with vision of the movements. Moreover, patients were also slower to mentally simulate the movements than to execute the task without vision of the movements.

60 years (mean: 35.1 years) and matched for educational level.

All subjects were able to perform both motor tasks without complaining of significant fatigue. They did not complain of any difficulty for imagery of the tasks. Patients and controls did not present involuntary movements of their arms or hands during the mental simulation of any of either.

In the course of performing the "finger tap task", some subjects failed to repeat correctly the 5 consecutive sequences of tapping the thumb against the second through the fifth fingers. All the wrong sequences were excluded from the trial and the performance was immediately repeated. There were 90 effective and 23 excluded trials. Ten of these trials were excluded from controls. Most excluded trials involved the execution of the task without vision of the movements (60.86\%). There were no failures during the execution of the "writing task" or in giving the order to stop the timing after finishing the execution of the task.

Patients and controls had some similarities in their performances in the "finger tap task" (Fig 1). There were not significant differences between them for motor execution of the task with vision of the movements $(p=0.666)$. However, patients with WC had a tendency to be slower than controls for the motor execution without vision $(p=0.190)$ and specialy for the mental simulation of the

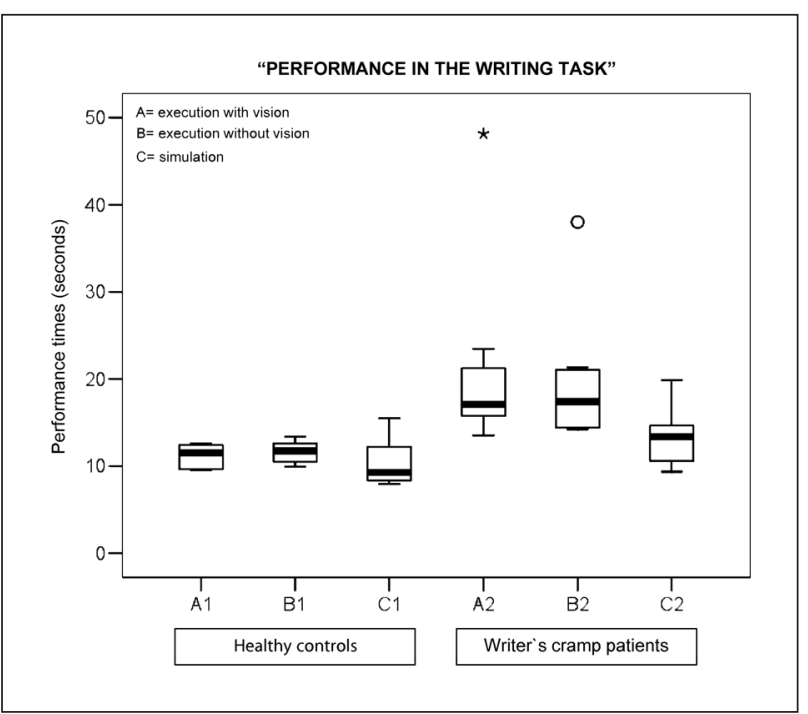

Fig 2. Box plot showing the performances of WC patients and healthy controls in the "writing task". Patients with WC were slower than controls to execute writing with vision of the movements, without vision of the movements and also to mentally simulate writing. The time spent by controls to execute and simulate the task did not differed significantly, while patients with WC were slower to execute writing than to mentally simuate it.

movements $(p=0.094)$. Patients and controls were significantly slower to mentally simulate (patients $p=0.008$, controls $p=0.012$ ) and to execute the "finger tap task" without visual control of the movements (patients $p=0.008$, controls $p=0.015$ ), than to execute the task with vision of the movements. Moreover, patients were also slower to mentally simulate the movements than to execute the task without vision of the movements $(p=0.008)$.

Patients and controls differed significantly in their performances in the "writing task" (Fig 2). Patients with WC were slower than controls to execute writing with vision of the movements ( $p=0.0001)$, without vision of the movements $(p=0.0001)$ and also to mentally simulate writing $(p=0.04)$. The PTs of the control subjects in the "writing task" were not significantly different in the three conditions of performance $(p=0.05)$ whereas the PTs of the patients with WC patients were longer for motor execution with vision $(p=0.021)$ and without vision $(p=0.021)$ of the movements than for the mental simulation of the "writing task".

We found strong correlations between the times spent for execution with vision and without vision of the movemens for the finger tap task and for the writing task for patients and controls (Table). Otherwise, there were not significant correlations between the times spent for execution and for simulation of the writing task by patients and controls and for the finger tap task by controls. However, patients with WC had significant correlations for simulation and for execution of the finger tap task. 
Table. Spearman's correlation coefficient between the performance times of patients with WC and healthy control subjects of the writing task and the finger tap task.

\begin{tabular}{|c|c|c|c|c|}
\hline & \multicolumn{2}{|c|}{ Patients with WC } & \multicolumn{2}{|c|}{ Control subjects } \\
\hline & Execution without vision & Simulation & Execution without vision & Simulation \\
\hline & \multicolumn{4}{|c|}{ Finger tap task } \\
\hline Execution with vision & 0.90 & 0.91 & 0.88 & 0.48 \\
\hline of movements & $p=0.001^{*}$ & $p=0.001^{*}$ & $p=0.002^{*}$ & $p=0.18$ \\
\hline Execution without & 1 & 0.78 & 1 & 0.23 \\
\hline \multirow[t]{2}{*}{ vision of movements } & & $\mathrm{p}=0.01^{*}$ & & $p=0.54$ \\
\hline & \multicolumn{4}{|c|}{ Writing task } \\
\hline Execution with vision & 0.91 & -0.11 & 0.85 & 0.25 \\
\hline of movements & $p=0.001^{*}$ & $p=0.76$ & $p=0.004^{*}$ & $p=0.51$ \\
\hline Execution without & 1 & 0.05 & 1 & 0.45 \\
\hline vision of movements & & $p=0.89$ & & $p=0.22$ \\
\hline
\end{tabular}

${ }^{*} \mathrm{p}<0.05$

\section{DISCUSSION}

In this study we found that patients with WC were slower than control subjects to execute and also to simulate a writing task. Otherwise, they also had a tendency to be slower to simulate a simple repetitive finger tap task, despite their performances in the motor execution of this task were very close to that attained by the healthy control subjects. These findings suggest that in WC there is a significant slowing in the mental process enrolled in the $\mathrm{KMI}$, and that motor imagery may unmasks subclinical involvement of other apparently unaffected manual tasks.

$\mathrm{KMI}$ is an introspective kinesthetic feeling of moving the limb as to mentally reproduce its own execution. Its physiological basis shows several parallels with motor execution'. Functional studies showed that KMI activates almost the same cerebral areas involved in movement, and some intrinsic physiological features of the movements are also preserved during $\mathrm{KMI}^{1,3,13}$. It is argued that one of these preserved features is the high resemblance between the time spent to execute and to simulate the same movement, supporting the view that $\mathrm{KMI}$ and motor execution share common neural structures ${ }^{2,3,5,14}$. It is thought that $\mathrm{KMl}$ is encoded in an internal program that relies in the same representations of motor execution and keeps untouched the temporal relationship between them, so that the time spent to simulate or to execute an action should be similar ${ }^{1,4,15,16}$. Despite the strong agreement about this topic in the literature, we did not find significant correlations between the times spent to execute and to simulate the hand movements in healthy controls. We were not able to explain this unexpected finding. However, our results in healthy subjets were very close to that obtained in previous studies with similar design ${ }^{2}$.

The main clinical abnormalities in WC are present during the execution of hand movements, when the dyston- ic contractions would be produced by an improper functioning of a sensorimotor link which could lead to abnormalities in the control of the movement ${ }^{17}$. Slowness for writing seems to be mainly related to the clumsiness for the execution of movements due to the abnormal muscular contractions ${ }^{18-23}$. However, during $\mathrm{KMI}$, the motor pathways are only partially activated and probably could not account for the abnormalities that we observed. The fact that the the mental effort to simulate handwriting could not elicit involuntary muscle contractions in our patients, suggest that the mechanisms of muscular activity blockade during simulation of movement was not impaired in simple WC. So, we would not expect at first that peripheral influences could had intervened with the process of $\mathrm{KMI}^{1,3}$. Then, our findings suggest that part of the motor slowness observed during writing in WC patients may be due to a primary slowing in the motor planning processes.

There are sufficient data indicating that patients with WC present many abnormalities preceding the execution of the movements ${ }^{8-11}$. The task-specific character of the disease also suggests that the abnormalities may be directly linked to dysfunctions of a specific motor plan or in the linkage between the motor plan and its proper efector, or both ${ }^{6}$. The mechanism associated with slowing of kinesthetic imagery in patients with WC is unknown. Functional studies suggest that basal ganglia are involved in the process of $\mathrm{KMI}^{1,13}$, and there are reports showing that the pathological involvement of this system may induce abnormalities in KMI. Some studies demonstrated that patients with Parkinson's disease were slower than normal subjects regarding mental simulation of simple hand movements and rotational tasks ${ }^{2,16}$. However in WC there are many findings indicating that in addition to the basal ganglia there are abnormalities in primary motor cor- 
tex, prefrontal motor areas and also in the somatosensory $\operatorname{areas}^{24-26}$, and there appear to be distinct cortico-subcortical neural circuits involved in imagined movements including bilateral premotor, prefrontal, supplementary motor and left parietal areas ${ }^{27}$.

The primary motor cortex is not the main suspected area for KMI slowing since it is not essential for imagery, and we know that damage restricted to the primary motor area does not result in impairment of $\mathrm{KMl}^{3,28}$. Somatosensory areas are also dysfunctional in focal hand dystonia and we cannot definitely rule out their participation in KMI deficits, since parietal lesions were found to disturb the chronometry of imagined finger movements despite the fact that parietal activation is often absent during kinesthetic imagery of simple movements ${ }^{3,15}$. Our preferential hypothesis was that the kinesthetic KMI abnormalities in WC are due to dysfunctions in the prefrontal motor areas produced by abnormal striatofrontal projections since the posterior SMA and the premotor cortex seems to be the predominant areas involved in movement imagery ${ }^{3}$.

Previous activation studies in patients with dystonia have failed to show abnormalities during mental simulation of movements ${ }^{24}$. However, recent findings showed that patients with WC were slower than controls in performing a visual imagery task involving rotations of the hands but not of the feet ${ }^{29}$. Visual imagery must be differentiated from kinesthetic motor imagery since do not activate the motor system as the later ${ }^{3}$. In addition, functional MRI studies have shown abnormalities in cortical activation during imagination of hands movements in secondary dystonia ${ }^{14}$. These findings are converging to demonstrate that patients with WC have a global impairment in $\mathrm{KMI}$ that is worst for the task and body area affected by the abnormal movements. The finding that our patients with simple WC also had a tendency for slower simulation of the finger tap task may disclose a subclinical involvement of other manual tasks.

In our experiment, the variable evaluated was the time spent to perform and to simulate each motor sequence, what is a very simple way to study a complex cognitive phenomenon. However, we may argue that the expected low sensitivity of this method just strengthened our findings. Our observations in normal subjects were very close to those reported by some previous studies, suggesting that our findings are reliable $e^{2}$. Another critical point is that it is pratically impossible to control for the quality of imagery. We tried to overcome possible timing errors during acquisition of KMI by including subjects with high educational level, subjectively checking their sensation of vividness of the simulated movements and closely check the compliance of individuals to promptly advise the exact moment when the simulation was ended.
We also need to stand out an alternative hypotheis for our findings that can not be completely ruled out. It is possible that the slowing in the simulation of writing in patients with WC may only represent a proportional readaptation of the internal simulation of the movements to the slowing of the execution of the movements. This adaptative response would be due to an internal control system that would mediate a change in the simulation times that would be proportional to the slowing in the execution times ${ }^{16}$. We can argue against this hypothesis that we disclosed slowing in the simulation of the finger tap task by patients with WC without any accompanying slowing in the execution of the movements. Also, there was not correlation between the times spent to write and to simulate writing by patients, what was predicted by this hypothesis.

In conclusion, patients with WC seem to have slowing in the processes of mental simulation of hand movements that is not specific for writing.

\section{REFERENCES}

1. Jeannerod M, Decety J. Mental motor imagery: a window into the representational stages of action. Curr Op Neurobiol 1995;5:727-732.

2. Dominey P, Decety J, Broussolle E, Chazot G, Jeannerod M. Motor imagery of a lateralized sequential task is asymmetrically slowed in hemi-Parkinson's patients. Neuropsychologia 1995;33:727-741.

3. Lotze M, Halsband U. Motor imagery. J Physiol (Paris) 2006;99: 386-395.

4. Decety J, Michel F. Comparative analysis of actual and mental movement times in two graphic tasks. Brain Cog 1989;11:87-97.

5. Stephan KM, Fink GR, Passingham RE, et al. Functional anatomy of the mental representation of upper extremity movements in healthy subjects. J Neurophysiol 1995;73:373-386.

6. Hallett M. Pathophysiology of writer's cramp. Human Mov Sci 2006;25:454-463.

7. Sheehy MP, Marsden CD. Writers' cramp-a focal dystonia. Brain 1982;105:461-480.

8. Deuschl G, Toro C, Matsumoto J, Hallett M. Movement-related cortical potentials in writer's cramp. Ann Neurol 1995; 38:862-868

9. Van der Kamp W, Rothwell JC, Thompson PD, Day BL, Marsden $\mathrm{CD}$. The movement-related cortical potential is abnormal in patients with idiopathic torsion dystonia. Mov Disord 1995;10(5):630-633.

10. Odergren T, Stone-Elander S, Ingvar M. Cerebral and cerebellar activation in correlation to the action-induced dystonia in writer's cramp. Mov Disord 1998;13:497-508.

11. Hamano T, Kaji R, Katayama M, et al. Abnormal contingent negative variation in writer's cramp. Clin Neurophysiol 1999; 110:508-515.

12. Burke RE, Fahn S, Marsden CD, Bressman SB, Moskowitz C, 
Friedman J. Validity and reliability of a rating scale for the primary torsion dystonias. Neurology 1985;35:73-77.

13. Szameitat AJ, Shen S, Sterr A. Motor imagery of complex everyday movements. An fMRI study. NeuroImage 2007;34:702-713.

14. Lehericy S, Gerardin E, Poline JB, et al. Motor execution and imagination networks in post-stroke dystonia. Neuroreport 2004;15:1887-1890.

15. Sirigu A, Duhamel JR, Cohen L, Pillon B, Dubois B, Agid Y. The mental representation of hand movements after parietal cortex damage. Science (New York) 1996;273:1564-1568.

16. Sabate M, Gonzalez B, Rodriguez M. Adapting movement planning to motor impairments: the motor-scanning system. Neuropsychologia 2007;45:378-386.

17. Kaji R, Rothwell JC, Katayama M, et al. Tonic vibration reflex and muscle afferent block in writer's cramp. Ann Neurol 1995; 38:155-162

18. Von Reis G. Electromyographical studies in writer's cramp. Acta Med Scand 1954;149:253-260.

19. Hughes M, McLellan DL. Increased co-activation of the upper limb muscles in writer's cramp. J Neurol Neurosurg Psychiatry 1985;48:782-787.

20. van der Kamp W, Berardelli A, Rothwell JC, Thompson PD, Day BL, Marsden CD. Rapid elbow movements in patients with torsion dystonia. J Neurol Neurosurg Psychiatry 1989; 52:1043-1049.

21. Agostino R, Berardelli A, Formica A, Accornero N, Manfredi M. Sequential arm movements in patients with Parkinson's disease, Huntington's disease and dystonia. Brain 1992;115: 1481-1495.

22. Inzelberg R, Flash $\mathrm{T}$, Schechtman E, Korczyn AD. Kinematic properties of upper limb trajectories in idiopathic torsion dystonia. J Neurol Neurosurg Psychiatry 1995;58:312-319.

23. Berardelli A, Hallett M, Rothwell JC, et al. Single-joint rapid arm movements in normal subjects and in patients with motor disorders. Brain 1996;119:661-674.

24. Ceballos-Baumann AO, Brooks DJ. Activation positron emission tomography scanning in dystonia. Adv Neurol 1998;78: 135-152.

25. Bara-Jimenez W, Catalan MJ, Hallett M, Gerloff C. Abnormal somatosensory homunculus in dystonia of the hand. Ann Neurol 1998;44:828-831.

26. Tinazzi M, Frasson E, Polo A, et al. Evidence for an abnormal cortical sensory processing in dystonia: selective enhancement of lower limb P37-N50 somatosensory evoked potential. Mov Disord 1999;14:473-480.

27. Gerardin E, Sirigu A, Lehericy S, et al. Partially overlapping neural networks for real and imagined hand movements. Cereb Cortex 2000;10:1093-1104.

28. Sirigu A, Cohen L, Duhamel JR, et al. Congruent unilateral impairments for real and imagined hand movements. Neuroreport 1995;6:997-1001.

29. Fiorio M, Tinazzi M, Aglioti SM. Selective impairment of hand mental rotation in patients with focal hand dystonia. Brain 2006;129:47-54. 